\title{
Thyroid hormones induce activation of rat hepatic stellate cells through increased expression of p75 neurotrophin receptor and direct activation of Rho
}

\author{
Isabel Zvibel ${ }^{1}$, Dikla Atias ${ }^{1,2}$, Adam Phillips ${ }^{1}$, Zamir Halpern ${ }^{1,2}$ and Ran Oren ${ }^{1,2}$
}

We have previously shown that hyperthyroidism is detrimental for liver fibrosis and in this study we have investigated the mechanisms regulating triiodothyronine (T3) and L-thyroxine (T4) activation of hepatic stellate cells (HSC). Expression of $\alpha$-smooth muscle actin ( $\alpha$ SMA) and p75 neurotrophin receptor (p75NTR) was determined by western blot analyses and transient transfection of the promoters. Rho activation was assayed using a pull-down assay and by ELISA. Expression of thyroid hormone receptor $\alpha 1$ decreases, whereas T4 receptor integrin $\alpha \mathrm{V} \beta 3$ increases, with transdifferentiation of HSC to myofibroblasts. T3 and T4 enhance HSC activation, without affecting proliferation or phosphorylation of mitogen-activated protein kinase, signal transducer and activator of transcription 3 or Akt. Addition of $10^{-7} \mathrm{M} \mathrm{T3}$ or T4 to thyroid hormone-depleted serum induces a twofold increase in activation marker $\alpha$ SMA, as well as upregulation of p75NTR protein levels. Both hormones enhance transcription of $\alpha$ SMA and p75NTR. We report a novel signaling pathway for thyroid hormones, activation of Rho. T4 induces activation of Rho acting through $\alpha \mathrm{v} \beta 3$ integrin, and the activation is abolished by the T4 antagonist, tetraiodothyroacetic acid, by peptide RGD and by a function-blocking antibody to integrin $\beta 3$. T3 and T4 increase phosphorylation of non-muscle myosin light chain II, a downstream signal to Rho/Rho-kinase activation. T3 also induces expression of tumor necrosis factor- $\alpha$. In vivo, administration of T3 or T4 together with thioacetamide (TAA) enhances fibrosis after 3 weeks, compared with the TAA-treated group, accompanied by increased $\alpha$ SMA in T3- and T4-treated groups, and of p75NTR in T4-treated rats. Thyroid hormones enhance activation of HSC through increased p75NTR and $\alpha$ SMA expression and activation of Rho, therefore accelerating development of liver fibrosis.

Laboratory Investigation (2010) 90, 674-684; doi:10.1038/labinvest.2010.48; published online 15 March 2010

KEYWORDS: hepatic stellate cells; liver fibrosis; p75 neurotrophin receptor; Rho activation; thyroid hormones

Chronic liver injury caused by viral hepatitis, alcohol and drugs results at first in fibrosis, and if the injury persists, leads to liver cirrhosis. The main source of the scar tissue during liver fibrosis and cirrhosis is the hepatic stellate cells (HSC). ${ }^{1,2}$ On activation, HSC undergo proliferation and differentiation, ${ }^{1,2}$ becoming myofibroblast-like $\alpha$-smooth muscle actin ( $\alpha \mathrm{SMA})$-positive cells that produce extracellular matrix proteins, particularly type I collagen. ${ }^{1,2}$

We have previously shown that hypothyroidism, induced chemically or surgically, prevents liver cirrhosis in a thioacetamide (TAA) rat model of fibrosis ${ }^{3}$ and recent studies show that hypothyroidism also helps regression of established liver cirrhosis. ${ }^{4}$
Thyroid hormones, triiodothyronine (T3) and L-thyroxine (T4) have central roles in growth, differentiation and metabolism, acting mainly through transcriptional regulation of target genes. ${ }^{5}$ The main circulating thyroid hormone, T4, is deiodinated inside cells by various deiodinases and becomes T3. T3 enters the nucleus and binds to nuclear thyroid hormone receptors, bound to target genes containing thyroid response elements (TRE). ${ }^{5}$ The two major receptor isoforms, thyroid hormone receptor $\alpha 1$ and $\beta 1$ (TR $\alpha 1$ and TR $\beta 1)$, are encoded by two separate genes and have tissue-specific distribution, with liver expressing mainly TR $\beta 1$, and heart expressing TR $\alpha 1 .^{5}$ We have shown that an immortalized hepatic stellate cell line, HSC-T6, expresses TR $\alpha 1$, but not

\footnotetext{
${ }^{1}$ Liver Unit, Department of Gastroenterology, Tel Aviv Sourasky Medical Center, Tel Aviv, Israel and ${ }^{2}$ Sackler School of Medicine, Tel Aviv University, Ramat Aviv, Israel Correspondence: Dr I Zvibel, MD, Department of Gastroenterology, Tel Aviv Sourasky Medical Center, Weizman 6, Tel Aviv 64239, Israel.

E-mail: isab@tasmc.health.gov.il

Received 5 October 2009; revised 2 November 2009; accepted 29 November 2009
} 
$\operatorname{TR} \beta 1$, whereas primary hepatocytes express both. ${ }^{6}$ Recently, T4 was shown to bind and signal through cell-surface integrin $\alpha v \beta 3,{ }^{7}$ inducing proliferation in various cells expressing high levels of $\alpha \mathrm{v} \beta 3 .^{8}$ The T4-induced signal transduction pathway includes phosphorylation of signal transducer and activator of transcription 1 (STAT1), STAT3 and mitogen-activated protein kinase (MAPK) and their translocation to the nucleus. ${ }^{8}$ Moreover, silencing of integrin $\alpha \mathrm{v} \beta 3$ using siRNA, or blocking the signaling of this receptor, induces HSC apoptosis. ${ }^{9}$

Recent studies have shed light on the function of p75 neurotrophin receptor (p75NTR) in HSC activation and show that in p75NTR $-/-$ mice, HSC are unable to become activated and to express $\alpha$ SMA. ${ }^{10}$ Interestingly, p75NTR is effective in activating HSC in the absence of its ligand, nerve growth factor (NGF), signaling through activation of guanosine triphosphatase Rho. ${ }^{10}$ Activation of members of Rho GTPase is reported to be crucial for HSC activation, as Rho inhibition attenuates liver fibrosis in several in vivo models. ${ }^{11,12}$

Quiescent HSC do not express p75NTR, but start expressing it on activation, ${ }^{13}$ whereas hepatocytes do not express this receptor. ${ }^{14}$ Recent studies show that hyperthyroidism induces expression of p75NTR in normal liver. ${ }^{15}$

On the basis of our previous studies and on studies describing the role of p75NTR in HSC activation, we have investigated the connection between thyroid hormones and activation of primary HSC in vivo and in vitro, and delineated the mechanisms involved, including transcription of p75NTR and Rho activation, leading to increased expression of $\alpha$ SMA.

\section{MATERIALS AND METHODS} Isolation of Primary Rat HSC

Livers of female rat Wistar (retired breeders) were perfused with Gey's balanced salt solution (GBSS), then GBSS with $100 \mathrm{mg}$ collagenase (Worthington Biochemical Corporation, NJ, USA) and $130 \mathrm{mg}$ pronase (Roche Diagnostics, Mannheim, Germany). The digested liver was minced and incubated with $100 \mathrm{ml}$ of GBSS with $25 \mathrm{mg}$ pronase, $25 \mathrm{mg}$ collagenase, $20 \mu \mathrm{g} / \mathrm{ml}$ DNAse I for $30 \mathrm{~min}$ at $37^{\circ} \mathrm{C}$ with 200 r.p.m. shaking. HSC were isolated on a $17.5 \%$ Nycodenz gradient centrifuged at $1400 \mathrm{~g}$ for $20 \mathrm{~min}^{.}$

\section{Primary HSC Culture Conditions}

Cells were cultured in DMEM with $10 \%$ fetal calf serum (FCS) and $100 \mu \mathrm{g} / \mathrm{ml}$ penicillin/streptomycin. To test effect of T3, we grown the cells for $24 \mathrm{~h}$ in serum-free DMEM with $10^{-7}$ M T3 (Sigma, St Louis, MI, USA). For other experiments, cells were grown in thyroid hormone-depleted serum medium (TDS), consisting of DMEM supplemented with $10 \%$ TDS. Depletion of T3 and T4 was obtained by overnight incubation of $2 \mathrm{~g}$ activated charcoal per $100 \mathrm{ml}$ serum at $4^{\circ} \mathrm{C}$, followed by centrifugation and filtration. ${ }^{16,17}$

\section{Proliferation Assays}

Proliferation was by cell counting (using a Coulter counter), by a proliferation kit EZ4U based on formation of tetrazolium salts (Biomedica Medizinprodukte, Vienna, Austria) and by BrdU incorporation (Exalpha Biologicals Inc., Watertown, MA, USA).

\section{Western Blots}

Equal amounts of total protein were separated by SDS-PAGE and blotted onto Hybond C extra. Blots were incubated with antibodies for TR $\alpha 1$ and TR $\beta 1$ (Affinity Bioreagents, Golden, CO, USA), $\alpha \mathrm{v}, \alpha \mathrm{SMA}$, PDGF receptor $\beta$, pMAPK (erk1/erk2), erk2, akt 1/2, STAT3 (Santa Cruz Biotechnology, Santa Cruz, CA, USA), p75NTR (Upstate, Lake Placid, NY, USA), pSTAT3, pAkt and p-non-muscle myosin light chain II (pMLC; Cell Signaling Technology, Danvers, MA, USA), then incubated with horseradish-peroxidase-conjugated secondary antibody and detected by chemiluminescence. Expression was normalized to glyceraldehydes-3-phosphate dehydrogenase (GAPDH) or $\beta$-actin.

\section{Immunohistochemistry}

Hepatic stellate cells were washed with PBS and fixed in methanol: acetone $(1: 1)$ for $10 \mathrm{~min}$ at $-20^{\circ} \mathrm{C}$. Cells were blocked for $30 \mathrm{~min}$ in PBS with $10 \%$ FCS, incubated for $1 \mathrm{~h}$ with $\alpha$ SMA antibodies (1:100; Santa Cruz Biotechnology), washed and incubated with secondary anti mouse-Cy3 (Jackson Immunoresearch Laboratories, Bar Harbor, ME, USA).

\section{Oil Red O Staining}

Hepatic stellate cells were cultured for 1, 2, 4, 5 and 7 days in TDS with or without $10^{-7} \mathrm{M}$ T3. Cells were fixed for $30 \mathrm{~min}$ in $10 \%$ formaldehyde and stained for $1 \mathrm{~h}$ with a $0.25 \%$ Oil Red O (Sigma) solution in propylene glycol.

\section{Rho Activation Assays}

Activated Rho was detected using a pull-down assay or an ELISA-based assay (Cytoskeleton, Denver, CO, USA). For the pull-down assay, 2, or 3 days and 5 days cultures of HSC were kept for $48 \mathrm{~h}$ in serum-free DMEM. Cells were pretreated for 30 min with $20 \mu \mathrm{l}$ of a function-blocking antibody to $\beta 3$ integrin (BioLegend, San Diego, CA, USA; clone 2C9.G2) or $500 \mathrm{nM}$ RGD (arginine-glycine-aspartate) or $100 \mathrm{nM}$ tetraiodothyroacetic acid (tetrac; Sigma), then T4 $\left(10^{-7} \mathrm{M}\right)$ or T3 $\left(10^{-7} \mathrm{M}\right)$ were added for 15 or $30 \mathrm{~min}$ and cells were scraped in a $\mathrm{Mg}^{2+}$ lysis buffer. Equal amounts of protein were incubated with rhotekin-agarose beads for $45 \mathrm{~min}$ at $4^{\circ} \mathrm{C}$, beads were washed and Rho-GTP bound to the beads was separated by gel electrophoresis, blotted and membranes were incubated with an Rho monoclonal antibody (Upstate). For the active RhoA ELISA, 5-day HSC were kept for $48 \mathrm{~h}$ in serum-free DMEM, then treated for 15 min with $10^{-7} \mathrm{M}$ T3 or $\mathrm{T} 4$ and $100 \mathrm{nM}$ tetrac. Cell lysates were assayed according to the manufacturer's instructions. 


\section{Transient Transfections and Reporter Gene Assays}

The plasmid containing the $-764 \mathrm{bp} \alpha \mathrm{SMA}$ promoterluciferase was from Dr S Phan (University of Michigan, MI, USA). The plasmids containing the $-3724 /+13$ human p75NTR promoter-luciferase and a shorter promoter region, $-207 /+13$, were from Dr P. Barker (McGill University, Montreal, Canada).

Hepatic stellate cells were transfected with $2 \mu \mathrm{g}$ of the promoter of interest and $0.3 \mu \mathrm{g} \beta$-galactosidase expression vector with Gene Jammer reagent (Stratagene, La Jolla, CA, USA) and treated for $24 \mathrm{~h}$ in OptiMEM (Gibco-BRL) with $10^{-7} \mathrm{M} \mathrm{T} 3$ and $\mathrm{T} 4,2.5 \mathrm{nM}$ thyroid hormone receptor antagonist 1-850 (Calbiochem, Darmstadt, Germany), $10 \mu \mathrm{M}$ Rho-kinase (ROCK) inhibitor Y-27632 (AG Scientific, San Diego, CA, USA) and $100 \mathrm{nM}$ tetrac. Luciferase activity was determined using the Luciferase Assay Kit (Applied Biosystems, Bedford, MA, USA) and was normalized to $\beta$-gal activity.

\section{RT-PCR for Cytokines}

Total RNA extracted using an EZ-RNA kit (Biological Industries, Bet Haemek, Israel) was DNAse-treated and reverse-transcribed. The cDNAs were used for PCR, using the following primers: tumor necrosis factor- $\alpha$ (TNF $\alpha$ ): $5^{\prime}$-ggagtggatcaggctgtctc- $3^{\prime}, 5^{\prime}$-ccagatggggatagctggta- $3^{\prime}$; transforming growth factor- $\beta$ (TGF $\beta 1)$ : $5^{\prime}$-tacagggctttcgcttca gt-3', $5^{\prime}$-tggttgtagagggcaaggac- $3^{\prime}$; stromal-derived factor $1 \alpha$ $($ SDF- $1 \alpha): 5^{\prime}$-gagtcagacgcctgaggaac- $3^{\prime}, \quad 5^{\prime}$-atccttgggggtaggaa cac- $3^{\prime}$; monocyte chemoattractant protein $1(\mathrm{MCP}-1)$ : $5^{\prime}$ tagcatccacgtgctgtctc- $3^{\prime}, \quad 5^{\prime}$-tgaggtggttgtggaaaaga- $3^{\prime} ;$ p 75 NTR: $5^{\prime}$-tacagtggcggatatggtga- $3^{\prime}, 5^{\prime}$-ctctacctcctcacgcttgg- $3^{\prime} ; \quad$ GAPDH: $5^{\prime}$-agacagccgcatcttcttgt- $3^{\prime}, 5^{\prime}$-cttgccgtgggtagagtcat- $3^{\prime}$. The PCR reaction contained $2 \mu \mathrm{l}$ of cDNA reaction, $0.4 \mu \mathrm{M}$ of each primer, $200 \mu \mathrm{M}$ dNTP, $10 \mathrm{mM}$ Tris- $\mathrm{HCl}$ (pH 8.3), $50 \mathrm{mM}$ $\mathrm{KCl}, 1.1 \mathrm{mM} \mathrm{MgCl}_{2}, 0.01 \%$ gelatin, $2.5 \mathrm{U}$ RED TaqDNA polymerase (Sigma). After denaturation for $10 \mathrm{~min}$ at $94^{\circ} \mathrm{C}$, the PCR was started using 32 cycles at $94^{\circ} \mathrm{C}$ for $50 \mathrm{~s}$, $60^{\circ} \mathrm{C}$ for $50 \mathrm{~s}$ and $72^{\circ} \mathrm{C}$ for $50 \mathrm{~s}$, with a final $5 \mathrm{~min}$ elongation step at $72^{\circ} \mathrm{C}$.

In Vivo Induction of Early Fibrosis and Hyperthyroidism Male Wistar rats $(300 \mathrm{~g})$ were injected i.p. with $150 \mathrm{mg} / \mathrm{Kg}$ body weight TAA twice a week for 3 weeks. The groups of animals were: (1) control group receiving TAA $(n=5)$; (2) TAA and T3 $10 \mu \mathrm{g}$ per rat injected s.c. five times a week $(n=6)$; (3) TAA and T4 (Eltroxin) in the drinking water $(10 \mathrm{mg} / \mathrm{l})(n=6)$.

\section{Statistical Analysis}

Results are presented as fold inductions compared to control values considered $100 \%$ and are averages + s.d. of at least three separate experiments. Statistical significance was assessed using an unpaired Student's $t$-test with $P$-value $<0.05$ considered significant.

\section{RESULTS \\ Expression of TR $\alpha 1$ Decreases and $\alpha v$ Increases with HSC Transdifferentiation into Myofibroblasts}

Primary HSC undergo spontaneous, time-dependent activation in culture, with 2- to 4-day cultures considered quiescent, 7-day cultures becoming activated and 14-day cultured considered fully activated. We were interested to assess expression of T3 nuclear receptor TR $\alpha 1$, as well as expression of the newly described T4 receptor integrin $\alpha \mathrm{v} \beta 3$, as a function of HSC activation. TR $\alpha 1$ expression in primary cultures of HSC has been assessed using TR $\alpha 1$-specific antibodies (not cross-reactive with TR $\alpha 2$ or TR $\beta 1$ ). Expression of TR $\alpha 1$ is high in 4-day (quiescent) and 7-day (activated) HSC, and dramatically decreases to only $30 \%$ in 14-day myofibroblasts (Figure $1 \mathrm{a}$ and b). TR $\beta 1$ has not been detected in HSC by TR $\beta 1$-specific antibodies (not cross-reactive with TR $\alpha 1$ or TR $\alpha 2$; data not shown). The pattern of expression of $\alpha \mathrm{v}$ and PDGF receptor- $\beta$ is the opposite of TR $\alpha 1$ during in vitro activation of HSC, with low expression of $\alpha \mathrm{v}$ and PDGF receptor- $\beta$ in quiescent cells and high expression in fully activated 14-day HSC (Figure la and $\mathrm{b}$ ).

We have tested whether in vivo activation of HSC also causes TR $\alpha 1$ reduction. Activation of HSC in vivo was obtained by 3 weeks injection of TAA, then HSC were isolated and tested for expression of TR $\alpha 1$ after 4, 7 and 14 days in culture. TR $\alpha 1$ is strongly reduced in HSC from TAA-treated rats compared with expression of TR $\alpha 1$ in 4-day quiescent HSC from normal rats (Figure 1c).

\section{Thyroid Hormones do not Affect HSC Proliferation}

T4 has been shown to induce proliferation of various cell types acting through integrin $\alpha \mathrm{v} \beta 3 .{ }^{8}$ The effect of T3 or T4 on proliferation of 7 and 14-day HSC has been determined by cell counting, by a proliferation kit based on formation of tetrazolium salts and by BrdU incorporation. T3 and T4 have no effect on proliferation tested by any of these methods (Figure 2a-c).

\section{Thyroid Hormones Induce Activation of HSC and Increase Expression of $\alpha \mathrm{SMA}$}

Because we have not observed effects of thyroid hormones on HSC proliferation, we have determined effects of these hormones on HSC activation. Spontaneous activation of HSC requires serum and is time dependent, so we needed to use serum for the duration of activation of HSC in culture, but use serum without thyroid hormones. Therefore, we have determined activation of HSC in the absence or presence of thyroid hormones using TDS. ${ }^{16,17}$ Both 4-day (not shown) and 7-day cultures of HSC grown in TDS show more aSMA-positive cells in TDS + T3 and TDS + T4 (Figure 3a). With activation, HSC lose their retinoic acid granules, so this is another marker of HSC activation. Most HSC after 4 days in culture still show retinoic acid granules determined by Oil Red staining in both TDS and TDS + T3 (Figure 3b). 

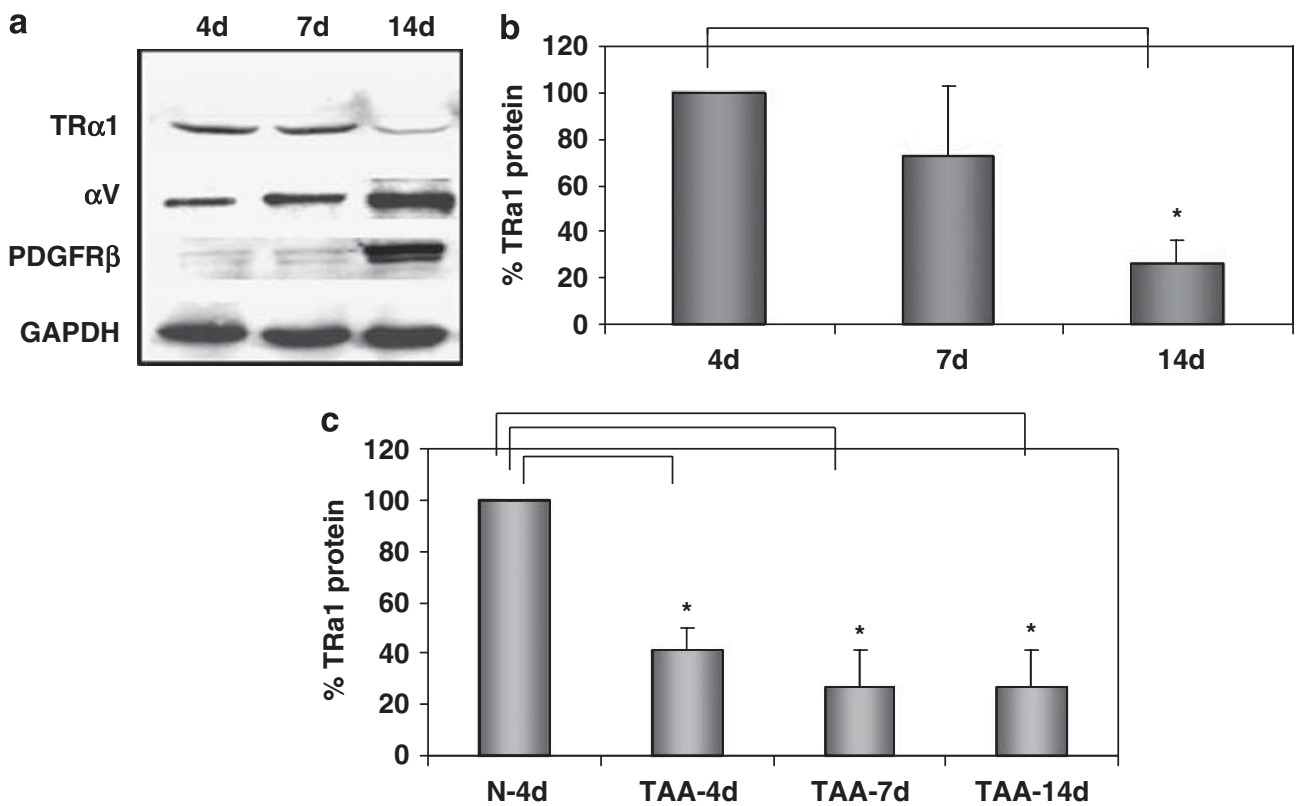

Figure 1 Expression of TR $\alpha 1$ is reduced in myofibroblasts. (a) Western blot showing TR $\alpha 1, \alpha \mathrm{V}$ and PDGF receptor $\beta$ in 4, 7 and 14-day HSC. (b) Means of fold-induction + s.d. of five westerns blot experiments with TR $\alpha 1$ normalized to GAPDH. ${ }^{*} P=0.000029$ vs 4 days. (c) TR $\alpha 1$ determined by western blot in HSC isolated from 3 weeks TAA-treated rats and compared with TR $\alpha 1$ in 4-day HSC cultures from normal rats (N). Results are means of fold-induction from three experiments + s.d. ${ }^{\star} P<0.03$.
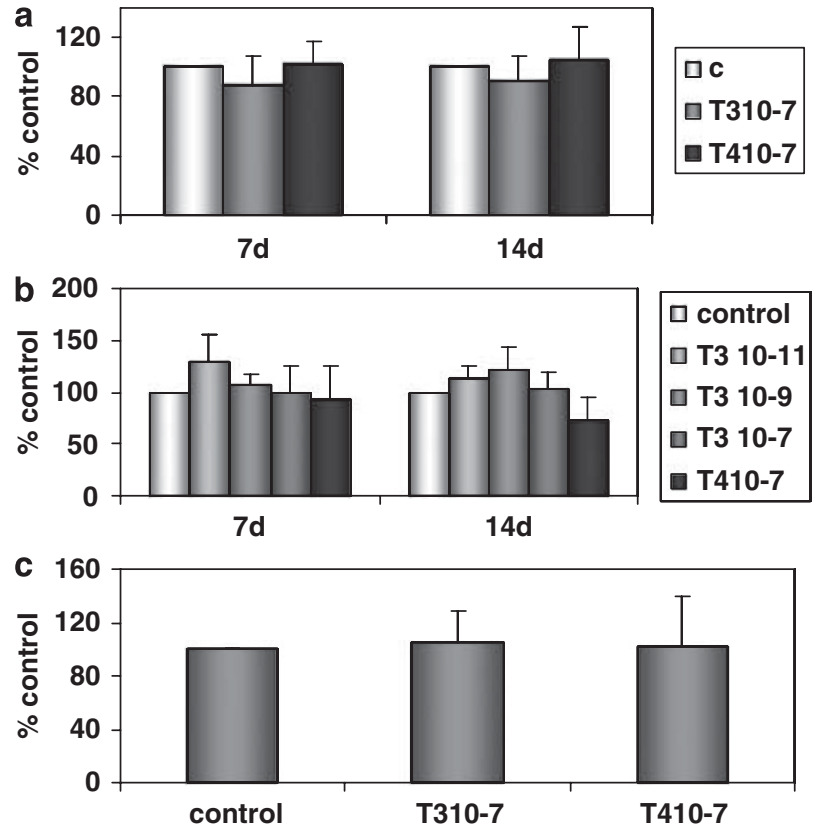

Figure 2 T3 and T4 do not affect HSC proliferation. (a) Proliferation of HSC determined by cell counting. Cells were serum-starved overnight in $0.5 \%$ FCS and grown with $10^{-7} \mathrm{M} \mathrm{T3}$ or $10^{-7} \mathrm{M} \mathrm{T} 4$ for $48 \mathrm{~h}$. Results are means of fold-induction + s.d. of five separate experiments in triplicates. (b) Proliferation determined by EZ4U kit. HSC were replated, serum-starved overnight in $0.5 \% \mathrm{FCS}$ and cultured for $48 \mathrm{~h}$ with $10^{-11}, 10^{-9}$ and $10^{-7} \mathrm{M} \mathrm{T3}$ or $10^{-7} \mathrm{M} \mathrm{T} 4$. Results are means of fold-induction + s.d. of three experiments in triplicates. (c) Proliferation determined by BrdU incorporation. HSC were replated, serumstarved overnight in $0.5 \% \mathrm{FCS}$ and cultured for $24 \mathrm{~h}$ with $10^{-7} \mathrm{M} \mathrm{T3}$ or T4. BrdU was added for $4 \mathrm{~h}$ and its incorporation determined using an ELISA assay. Results are means of fold-induction + s.d. of three experiments in triplicates.
However, although 5-day cultures in TDS have 70\% Oil Redpositive cells, HSC grown in TDS + T3 have only $50 \%$ Oil Red-positive cells (Figure 3b), suggesting faster activation of HSC in the presence of T3. After 7 days in culture, cells contain almost no Oil Red-positive granules (data not shown).

To quantitate expression of $\alpha \mathrm{SMA}$, we performed western blot analyses of HSC cultured for 14 days in TDS, with or without $10^{-7} \mathrm{M} \mathrm{T} 3$ and T4. Presence of T3 or T4 causes a twofold, statistically significant increase in the levels of $\alpha \mathrm{SMA}$ protein, compared with TDS alone (Figure $3 \mathrm{c}$ and $\mathrm{d}$ ). The same effects are observed in 7-day cultures (not shown).

We have next investigated whether $\mathrm{T} 3$ and $\mathrm{T} 4$ induction of $\alpha \mathrm{SMa}$ is transcriptionally mediated, as the $\alpha \mathrm{SMA}$ promoter contains a TRE at $-173 /-149 \mathrm{bp}$ and T3 induces $\alpha \mathrm{SMA}$ transcription in cardiomyocytes. ${ }^{17,18} \mathrm{~T} 3$ addition to 7 -day cultures of HSC induces a modest (20\%), but statistically significant increase in transcription (Figure $3 \mathrm{e}$ ), which is abolished in the presence of $2.5 \mathrm{nM}$ of the thyroid hormone receptor antagonist 1-850 (Figure 3e). Moreover, $\alpha \mathrm{SMA}$ transcription is known to be induced by Rho/ROCK signaling and the presence of $10 \mu \mathrm{M}$ of ROCK inhibitor Y-27632 reduces transcription of $\alpha$ SMA by itself, as expected, but also abolishes T3 induction of SSMA transcription, indicating that T3 upregulation of $\alpha \mathrm{SMA}$ transcription requires Rho/ ROCK signaling (Figure 3e).

\section{Thyroid Hormones Induce Expression of P75NTR}

We have examined other possible mechanisms responsible for HSC activation by thyroid hormones. A receptor crucial for differentiation of HSC, p75NTR, ${ }^{10}$ is upregulated in the livers 
a
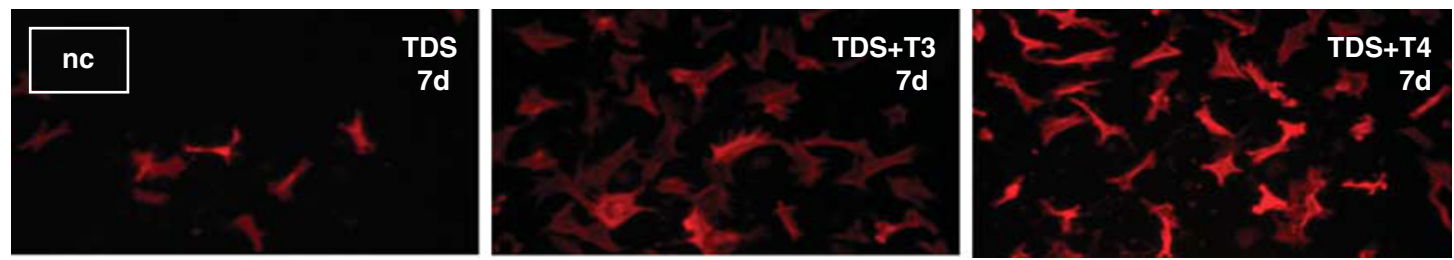

b
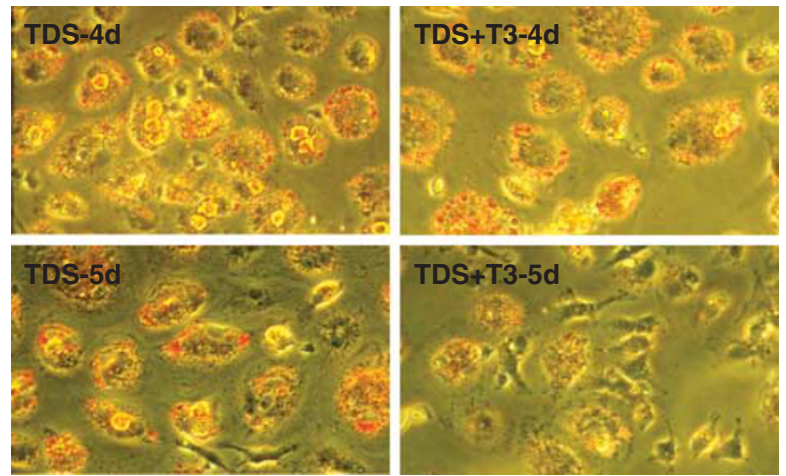

C

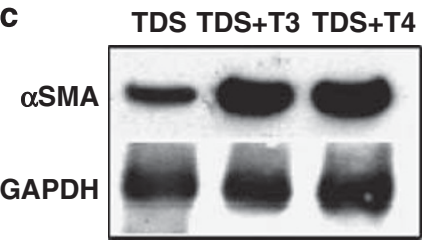

d

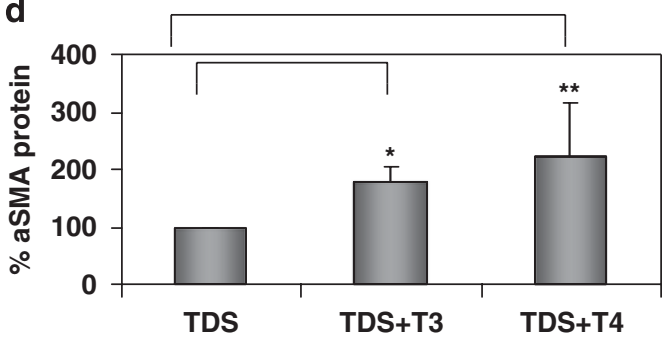

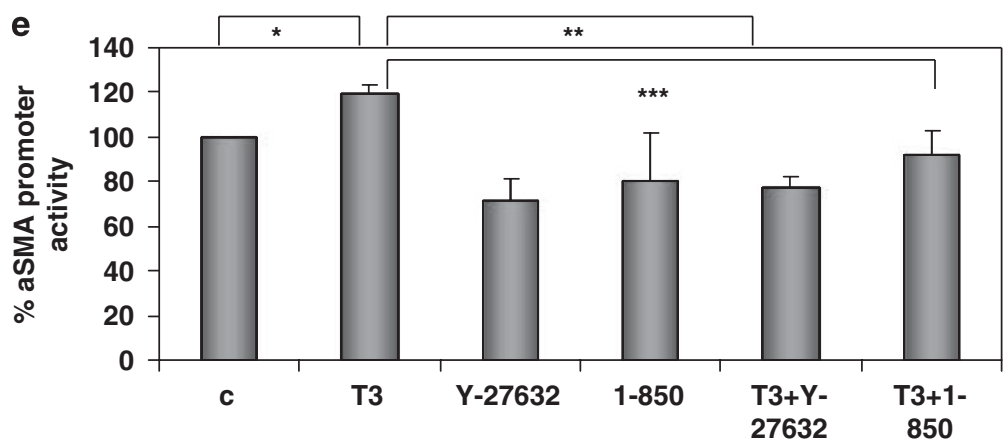

Figure 3 T3 causes more rapid activation of HSC and induces expression of $\alpha$ SMA in HSC. (a) Immunohistochemistry for $\alpha$ SMA expression in HSC cultured for 7 days in TDS, with or without $10^{-7} \mathrm{M} \mathrm{T3}$ or T4, showing more $\alpha$ SMA-positive cells in the presence of T3 and T4. nc in the first picture is staining with second antibody only; (b) Oil Red staining showing that after 5 days in culture, there are less Oil Red vesicles in HSC grown in TDS + T3. (c) Western blot showing $\alpha$ SMA in HSC cultured for 14 days in TDS with or without $10^{-7}$ M T3 or T4. (d) Results are means of fold-induction + s.d. of western blot experiments with $\alpha$ SMA normalized to GAPDH. ${ }^{\star} P=0.00007$ (six experiments); ${ }^{\star *} P=0.032$ (four experiments). (e) Effect of $10^{-7} \mathrm{M}$ T3 on transcription of the $-764 \alpha$ SMA promoter in 7-day HSC. Cells were treated overnight with $10^{-7} \mathrm{M}$ T3 in serum-free medium, with or without T3 inhibitor 1-850 $(2.5 \mathrm{nM})$ and ROCK inhibitor Y-27632 $(10 \mu \mathrm{M})$. Results are means of fold-induction + s.d. of four experiments in duplicates, with luciferase activity normalized to $\beta$-galactosidase activity. ${ }^{\star} P=0.002$ vs control; ${ }^{\star * P}=0.03$ vs T3; ${ }^{\star *} P=0.0003$ vs T3.

of hyperthyroid rats, following injection of T3 for 10 days. ${ }^{15}$ We have therefore assessed the effect of $\mathrm{T} 3$ on the expression of p75NTR in HSC. Expression of p75NTR is low in 7-day HSC cultures grown in TDS (Figure 4a), and is induced twoand threefold, respectively, in the presence of $10^{-7} \mathrm{M} \mathrm{T} 3$ and T4 in 14-day cultures, as shown by western blot (Figure 4a and $\mathrm{b}$ ) and by RT-PCR (Figure $4 \mathrm{c}$ and $\mathrm{d}$ ).

We have next determined whether T3 and T4 affected transcription of p75NTR, by transfecting vectors containing the luciferase reporter gene under the control of the proximal p75NTR promoter in 7-day HSC. We observed that $10^{-7} \mathrm{M}$ T3 and T4 enhance 1.4- and 1.7-fold, respectively, transcription of the full-length p75NTR promoter, -3724/ $+13 \mathrm{bp}$ and both hormones cause a twofold increase in the transcription of the shorter fragment, $-207 /+13 \mathrm{bp}$ (Figure 4e). Moreover, both T3 antagonist 1-850 and
T4 inhibitor tetrac abolish the transcriptional effect of T3 and T4 on the full-length p75NTR promoter (Figure 4f).

\section{T3 and T4 Signal through Rho Activation in HSC}

We have next studied signaling mechanisms induced by thyroid hormones, which can explain their effects on activation of HSC. Several signal transduction pathways have been shown for thyroid hormones: T4, through integrin $\alpha \mathrm{v} \beta 3$, induces phosphorylation of MAPK and STAT3, ${ }^{8}$ whereas $\mathrm{T} 3$, in addition to signaling through nuclear receptors TR $\alpha 1$ and TR $\beta 1$, triggers association of TR $\alpha 1$ with the $\mathrm{p} 85 \alpha$ subunit of phosphatidyl-inositol-3-kinase (PI3K), leading to Akt phosphorylation. ${ }^{19}$ Treatment of 7-day cultures of HSC with $10^{-7} \mathrm{M} \mathrm{T} 3$ or T4 for 30 min has no effect on phosphorylation of MAPK, Akt or STAT3 (Figure 5a). 

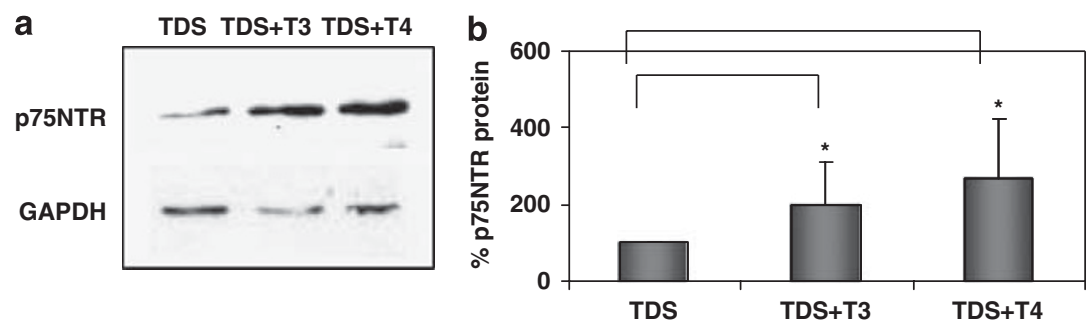

C
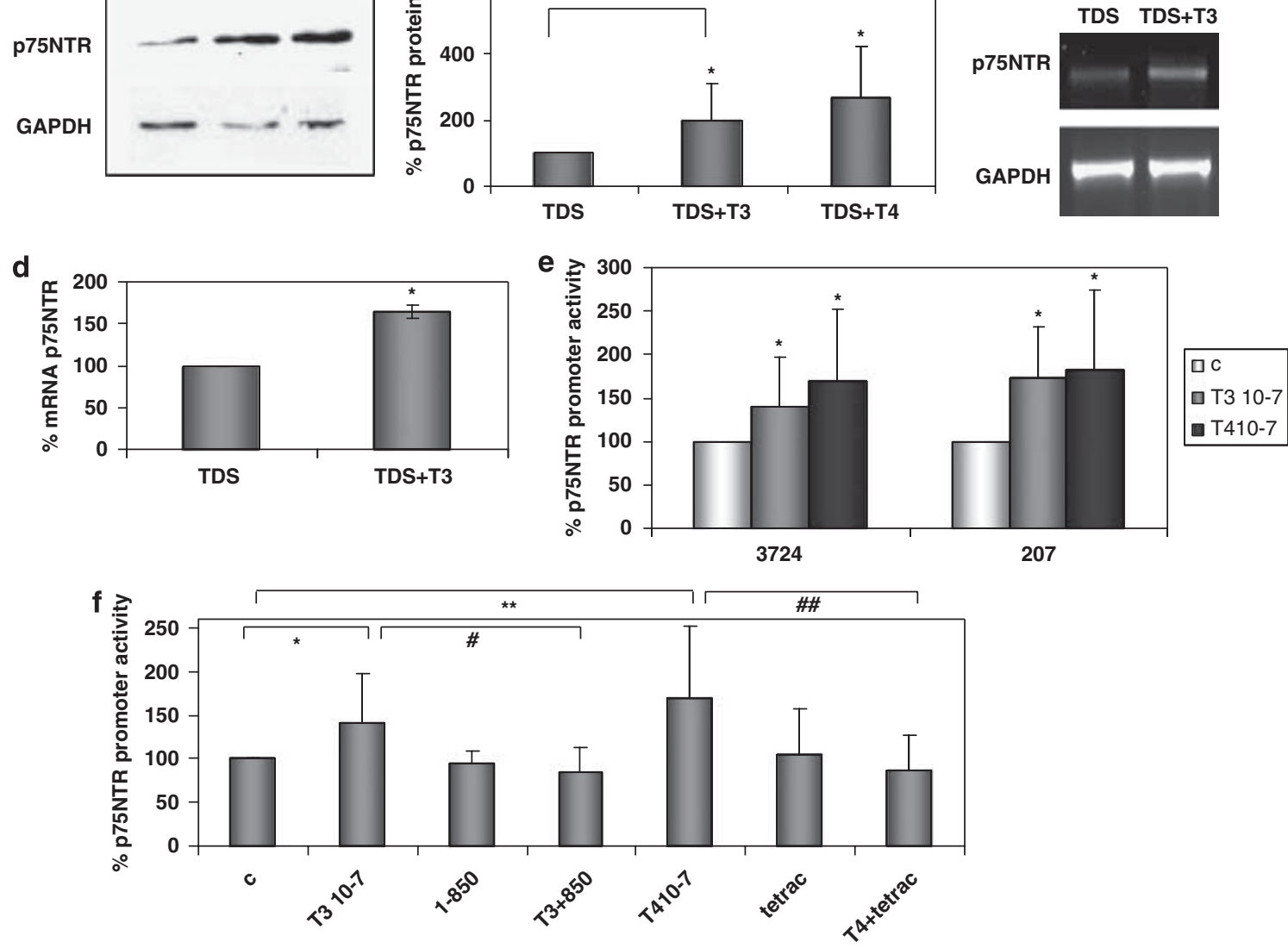

Figure 4 T3 and T4 induce expression of p75NTR. (a) Western blot analysis showing p75NTR in HSC grown for 7 days in TDS, with or without $10^{-7}$ M T3 or T4. (b) Results are means of fold-induction from five western blot experiments + s.d. of p75NTR normalized to GAPDH in 14 -day cultures. ${ }^{\star} P=0.03$. (c) RT-PCR showing expression of p75NTR in HSC grown for 14 days in TDS or TDS with $10^{-7} \mathrm{M} \mathrm{T3}$. (d) RT-PCR of p75NTR normalized to GAPDH, results are means of fold-induction + s.d. of four experiments. ${ }^{*} P=0.000005$. (e) Effect of $10^{-7} \mathrm{M}$ T3 or T4 in 7-day cultures on transcription of p75NTR using two fragments of the p75NTR promoter, the $-3724 /+13$ and the $-207 /+13$. Results are means of fold-induction + s.d. of five experiments. ${ }^{\star} P<0.05$ in one-tailed unpaired Student's $t$-test. (f) Effect of thyroid hormones on transcription of p75NTR using the $-3724 /+13$ promoter of human p75NTR in 7-day HSC. Cells were treated overnight with $10^{-7}$ M T3 or T4 in serum-free medium, with or without T3 inhibitor 1-850 (2.5 nM) and T4 inhibitor tetrac (100 nM). Results are means of fold-induction + s.d. of five experiments in duplicates, with luciferase activity normalized to $\beta$-galactosidase activity. ${ }^{\star} P=0.028$ vs control; ${ }^{* *} P=0.049$ vs control, ${ }^{\#} P=0.05$ vs T3; ${ }^{\# \#} P=0.036$ vs T4.

One of the known signals regulating activation of HSC is Rho activation, ${ }^{10}$ and p75NTR has been shown to induce Rho activation in the absence of its ligand NGF. ${ }^{10,20}$ We assume that T3 and T4 may enhance Rho activation either through increased expression of p75NTR, or may directly induce Rho activation. Rho activation has first been tested by pull-down assay with Rhotekin agarose beads. Both T3 and T4 strongly induce Rho activation in both 4- and 7-day HSC, and Rho activation by T4 is abolished by T4 antagonist, tetrac (Figure 5b). Pretreatment of cells with a functionblocking antibody to integrin $\beta 3$ or with RGD inhibits T4, but not T3, activation of Rho (Figure 5c). RhoA activation is also shown using ELISA. Both T3 and T4 activate RhoA in a dose-dependent manner after 15 min treatment, with a T4 dose of $10^{-8} \mathrm{M}$ sufficient for inducing RhoA activation (Figure 5d).
The effects of T3 and T4 have next been assayed on the downstream signaling of Rho and ROCK activation, which consists of phosphorylation of pMLC. We have determined effects of T3 and T4 in 5-day cultures of HSC and have observed that T4 induces phosphorylation of MLC after $30 \mathrm{~min}$, whereas T3 maximal effect is after $30 \mathrm{~min}$. Tetrac abolishes the effect of both hormones (Figure 5e).

\section{T3 Increases Expression of TNF $\alpha$}

Activated HSC are known to express many inflammatory and profibrotic cytokines. We have determined mRNA for various cytokines in HSC cultured in TDS, with or without $10^{-7} \mathrm{M}$ T3, for 4,7 and 14 days. There is a dramatic increase in SDF- $1 \alpha$ expression during HSC activation, with strong SDF-1 $\alpha$ expression in 14-day cultures (Figure 6a). T3 increases expression of TNF $\alpha$ and SDF-1 $\alpha$ in 4- and 7-day 
a

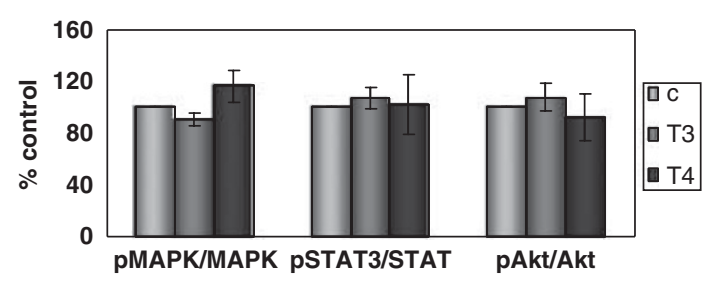

b $\quad$ C $\quad$ T3 $\quad$ T4 tetrac T4+tetrac

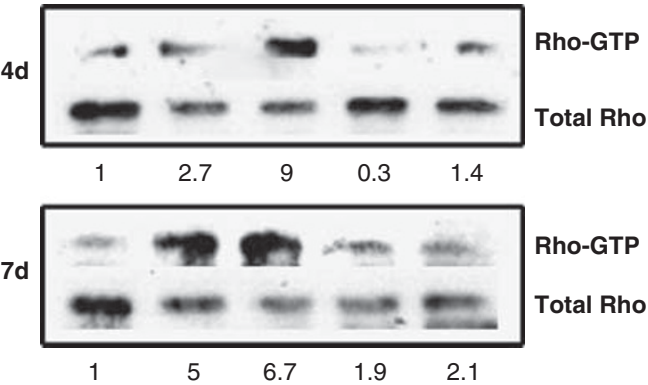

d

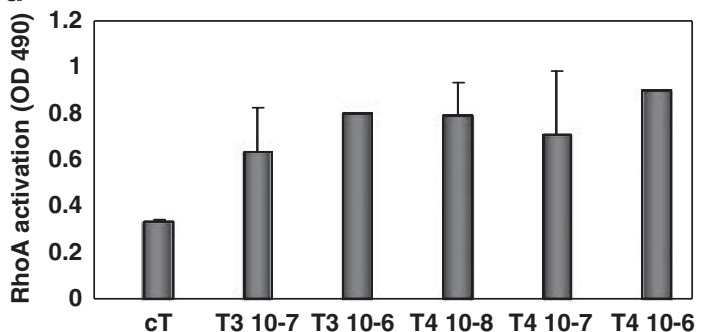

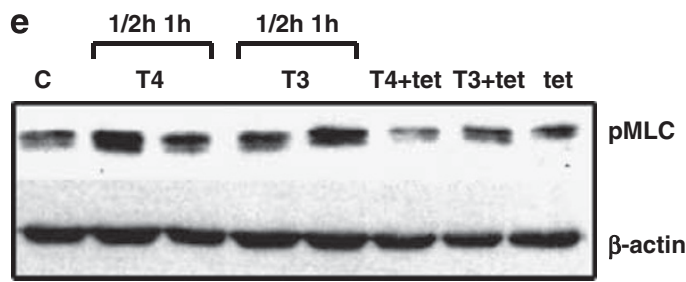

Figure 5 T3 and T4 induce Rho activation, but do not affect phosphorylation of MAPK, STAT3 or Akt in HSC. (a) T3 and T4 do not affect phosphorylation of MAPK, STAT3 and Akt. HSC were grown for 5 days in $10 \% \mathrm{FCS}$, serum-starved for $48 \mathrm{~h}$, then $10^{-7} \mathrm{M} \mathrm{T3}$ and T4 were added for 30 min. Results are means of fold-induction + s.d. of three experiments, with expression of pMAPK, pSTAT3 and pAkt normalized to erk2, STAT3 and Akt. (b) Representative western blot analysis showing activated Rho (Rho-GTP) after T3 and T4 treatment in 4- and 7-day HSC. HSC were grown for 2 or 5 days in 10\% FCS, serum-starved for $48 \mathrm{~h}$ and treated with $10^{-7} \mathrm{M} \mathrm{T3}$ for $30 \mathrm{~min}$, or $10^{-7} \mathrm{M} \mathrm{T} 4$ and $100 \mathrm{nM}$ tetrac for $15 \mathrm{~min}$. Rho-GTP was assayed using a pull-down assay. Total Rho expression is shown. Rho-GTP expression was normalized to total Rho, and is shown below the blots, as fold-induction vs control. Experiments were repeated qtwice with similar results. (c) Representative western blot showing activated Rho (Rho-GTP) after T3 and T4 treatment in 5-day HSC. HSC were grown for 3 days in $10 \% \mathrm{FCS}$, serum-starved for $48 \mathrm{~h}$ and pretreated for $30 \mathrm{~min}$ with $20 \mu \mathrm{l}$ (concentration $1 \mu \mathrm{g} / \mu \mathrm{l}$ ) function-blocking antibody to integrin $\beta 3$ and $500 \mathrm{nM}$ RGD. Then $10^{-7} \mathrm{M} \mathrm{T3}$ and $10^{-7} \mathrm{M} \mathrm{T4}$ were added for $15 \mathrm{~min}$ and Rho-GTP was assayed using a pull-down assay. Rho-GTP expression was normalized to total Rho, and is shown below the blots, as fold-induction vs control. (d) T3 and T4 induce RhoA activation. HSC were grown for 5 days in $10 \%$ FCS, serum-starved for $48 \mathrm{~h}$ and treated with various doses of T3 and T4 for $15 \mathrm{~min}$. Activated RhoA was determined using ELISA. Histogram shows representative experiment performed in duplicates, from three experiments with similar results. (e) T3 and T4 induce phosphorylation of non-muscle myosin light chain II. Representative western blot analysis showing pMLC in 5-day cultures of HSC. After 3 days in culture, cells were serum-starved for $48 \mathrm{~h}$, then treated with $10^{-7} \mathrm{M} \mathrm{T3}$ and T4 for $1 / 2$ or $1 \mathrm{~h}$, with or without $100 \mathrm{nM}$ tetrac. Antibodies to $\beta$-actin show equal protein loading.

cultures, with no effect on MCP-1 and TGF $\beta 1$ (Figure 6a). Moreover, short-term treatment with T3 also induces expression of TNF $\alpha$, but not of MCP-1 and TGF $\beta 1$, as shown after overnight treatment in serum-free medium in 14-day HSC (Figure $6 \mathrm{~b}$ and $\mathrm{c}$ ).

\section{Hyperthyroidism Accelerates Development of Liver Fibrosis and Enhances Activation of HSC In Vivo}

We have examined whether thyroid hormones also accelerate activation of HSC, not only in vitro, but also in vivo, using a rat model of TAA-induced fibrosis. Rats have received TAA, or TAA + T3 and TAA + T4, for a period of 3 weeks. Injection of T3 to normal rats for 10 days has been shown to induce liver damage, as determined by increased values for ALT and AST. ${ }^{17}$ We have obtained similar results in TAA + T3-treated rats, which have significantly higher ALT than TAA alone, but less ALT and AST than TAA + T4 (Table 1).

Thyroid-stimulating hormone values are lower in the $\mathrm{TAA}+\mathrm{T} 3$-treated animals and their total T3 is higher than TAA-treated rats, whereas animals receiving $\mathrm{T} 4$ have both elevated T3 and free T4 (Table 1). TAA + T3- and TAA + T4treated rats have a fibrosis score of 1.6 and 2.8, respectively, compared with 0.8 in rats treated with TAA alone (Table 1). Higher fibrosis score in TAA + T4- vs TAA + T3-treated rats is not due to increased hepatic damage, as ALT is lower in livers of TAA + T4 than in TAA + T3 (Table 1). Interestingly, T4 treatment resulted in significantly higher total T3 levels than treatment with T3 (Table 1). Collagen staining is observed in livers of TAA + T3- and TAA + T4-injected rats, but not in TAA-treated rats (Figure 7a). There is weak expression 

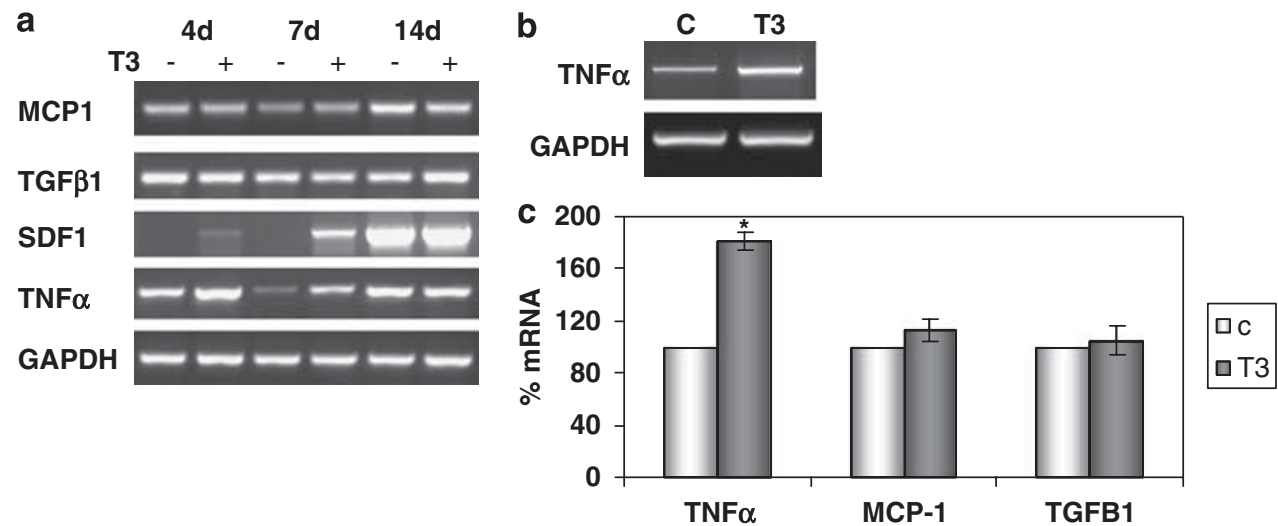

Figure 6 Effect of T3 on cytokine expression after long-term culture in TDS or after 24h treatment with T3. (a) Cytokine expression detected by RT-PCR in HSC cultured for 4, 7 and 14 days in TDS with or without $10^{-7} \mathrm{M}$ T3. (b) RT-PCR showing that T3 treatment for $24 \mathrm{~h}$ increases expression of TNF $\alpha$ in 14-day cultures. (c) Expression of TNF $\alpha$, MCP-1 and TGF $\beta 1$ by RT-PCR in HSC cultured for 14 days in $10 \%$ FCS, then changed to DMEM with or without $10^{-7} \mathrm{M} \mathrm{T3}$ for $24 \mathrm{~h}$. Results are means of fold-induction + s.d. of three experiments after normalization to GAPDH. ${ }^{*} P=0.00004$.

Table 1 Effect of TAA and hyperthyroidism on liver functions, thyroid hormones levels and fibrosis

\begin{tabular}{|c|c|c|c|c|c|c|c|}
\hline Treatment & ALT (U/I) & AST (U/l) & Alb $(g / l)$ & TSH $(\mathrm{mu} / \mathrm{l})$ & T3 (ng per $100 \mathrm{ml}$ ) & Free T4 (ng per $100 \mathrm{ml}$ ) & Fibrosis $^{a}$ \\
\hline $\mathrm{TAA}^{\mathrm{b}}$ & $161+61$ & $144+44$ & $40+0.8$ & $2.16+0.42$ & $50.3+4.3$ & $2.1+0.2$ & $0.8+0.4$ \\
\hline $\mathrm{TAA}+\mathrm{T}^{\mathrm{d}}$ & $249+49^{*, \#}$ & $168+26$ & $33+2$ & $0.032+0.008^{*}$ & 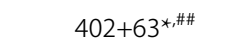 & $11.1+1.2^{*}$ & $2.8+0.8^{*}$ \\
\hline
\end{tabular}

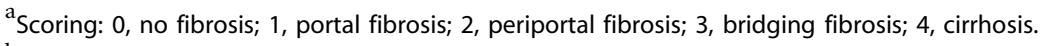

${ }^{\mathrm{b}}$ Control received TAA ( $n=5$ animals).

${ }^{\mathrm{C}} \mathrm{TAA}+\mathrm{T} 310 \mu \mathrm{g}$ per rat injected s.c. five times a week $(n=6)$.

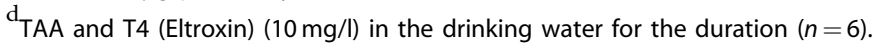

${ }^{*} P<0.01$ vs TAA; ${ }^{\#} P=0.03$ vs TAA + T3. ${ }^{\# \#} P=0.022$ vs TAA+T3.
}

of $\alpha$ SMA and p75NTR in normal rat liver, yet comparable in its levels to expression of both proteins in livers of rats treated for 3 weeks with TAA (Figure 7b). The source of $\alpha \mathrm{SMA}$ in the normal liver can be endothelial cells, and also 3-week treatment with TAA is only the beginning of activation of HSC, explaining weak levels of $\alpha \mathrm{SMA}$. Expression of $\alpha \mathrm{SMA}$ is increased in a statistically significant manner in the livers of both TAA + T3- and TAA + T4-treated rats, compared with rats receiving TAA (Figure $7 \mathrm{c}$ and $\mathrm{d}$ ). However, only $\mathrm{TAA}+\mathrm{T} 4$ treatment, but not TAA $+\mathrm{T} 3$, results in statistically higher levels of p75NTR (Figure 7e and f). We assume that T3 may enhance p75NTR expression at an earlier time, and as we observed that T3 induces a twofold increase and T4 a threefold increase of p75NTR in vitro (Figure 4b), T4 may also be more potent than $\mathrm{T} 3$ in enhancing expression of p75NTR (Figure 8).

\section{DISCUSSION}

We have found that thyroid hormones, T3 and T4, are important for activation of primary HSC both in vitro and in vivo. We show that T3 and T4 enhance activation of HSC by three different mechanisms: direct upregulation of $\alpha \mathrm{SMA}$, increased expression of p75NTR and rapid, direct activation of Rho. Activation of Rho is a novel signaling pathway, previously unreported for these hormones.

The profibrogenic effect of hyperthyroidism has been reported by several studies from our laboratory, where hyperthyroidism increases and hypothyroidism alleviates liver fibrosis in a TAA rat model, ${ }^{3,4}$ yet the mechanisms involved are unknown.

We show for the first time that TR $\alpha 1$ expression is regulated by the state of activation of HSC, as strongly activated HSC after 14 days in culture have reduced expression of TR $\alpha 1$, yet the same cells show increased levels of T4 receptor $\alpha \mathrm{v}$, as was previously reported. ${ }^{9}$ Interestingly, expression of other nuclear hormone receptors involved in lipid metabolism, such as peroxisome proliferator-activated receptors- $\gamma$, is also reduced in activated HSC, and overexpression of these receptors in activated HSC induces a quiescent phenotype. $^{21}$

The main effect of T3 and T4 is upregulation of $\alpha \mathrm{SMA}$ expression and accelerated activation of HSC in vitro, and the 

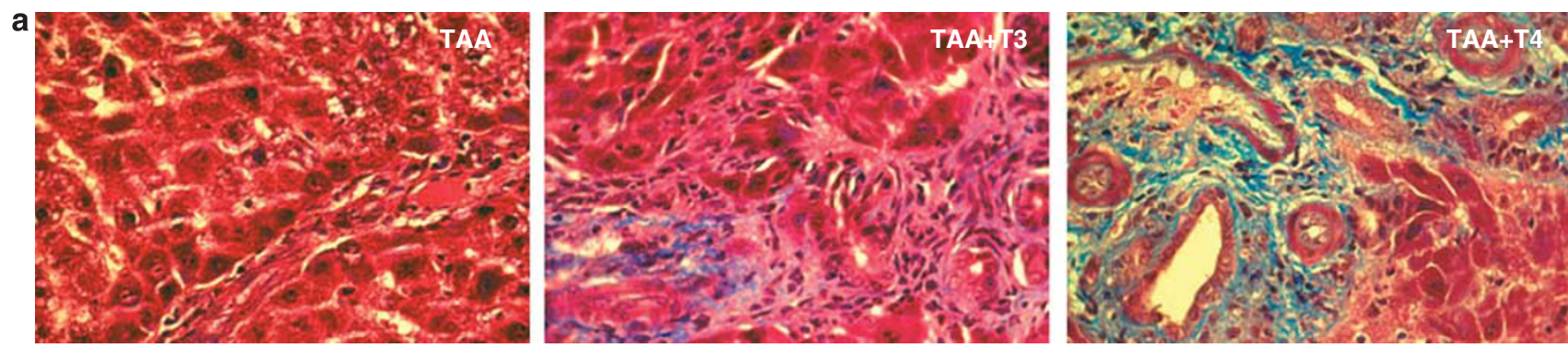

b

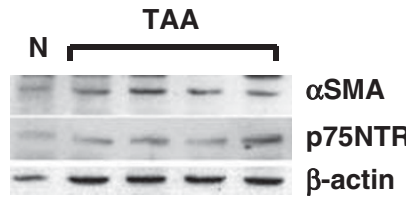

C
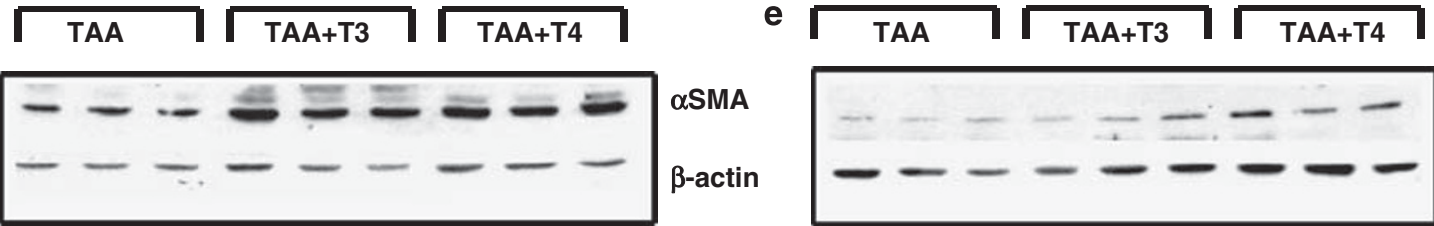

$\alpha$ SMA $\beta$-actin

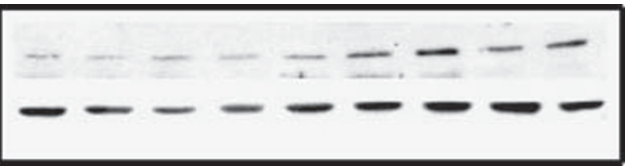

p75NTR

d
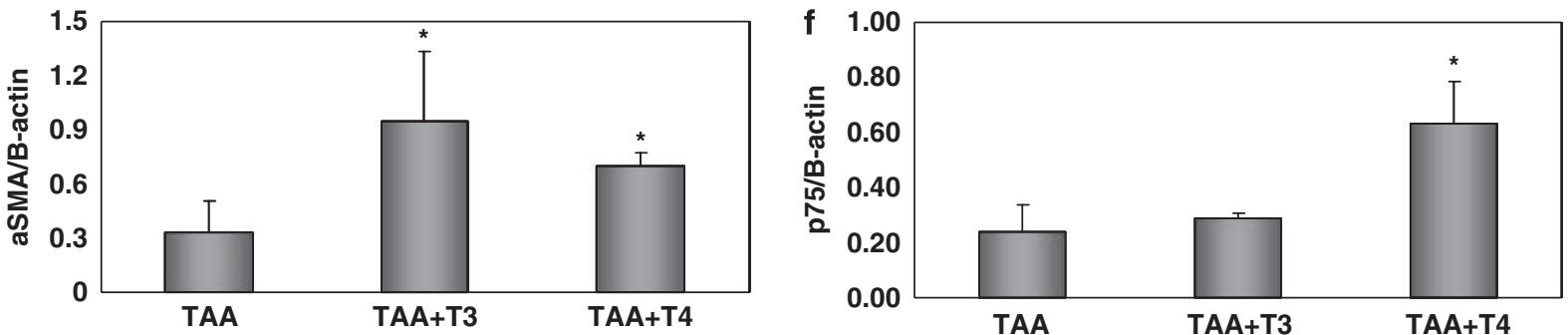

Figure 7 Hyperthyroidism induces fibrosis and enhances expression of $\alpha$ SMA in livers of TAA-treated rats. (a) Collagen expression as detected by Masson Trichrome staining of livers after 3 weeks treatment with TAA, TAA + T3 and TAA + T4. (b) Western blot analysis showing $\alpha$ SMA, p75NTR and $\beta$-actin expression in normal liver (N) and livers of rats injected for 3 weeks with TAA; (c) western blot showing the effect of TAA with or without T3 or T4 administration on $\alpha$ SMA expression. (d) Results are means + s.d. of $\alpha$ SMA normalized to $\beta$-actin $(n=3)$. ${ }^{*} p<0.05$ by unpaired one-tailed Student's $t$-test. (e) Western blot analysis showing the effect of TAA with or without T3 or T4 administration on p75NTR expression (f) Results are means + s.d. of p75NTR normalized to $\beta$-actin. ${ }^{\star} P=0.02$.

effect of T3 on $\alpha \mathrm{SMA}$ is transcriptional and abolished by T3 antagonist 1-850. Similar findings were reported for cardiomyocytes, where T3 enhances $\alpha \mathrm{SMA}$ transcription through $\mathrm{TR} \alpha 1$ binding to a TRE in the $\alpha \mathrm{SMA}$ promoter and T3 addition to TDS induces $\alpha$ SMA in a dose-dependent manner. ${ }^{17,18}$

Recently, it was reported that HSC from p75NTR-/mice failed to activate and did not express $\alpha \mathrm{SMA} .{ }^{10}$ We show that HSC grown in TDS have low levels of p75NTR and addition of $\mathrm{T} 3$ and $\mathrm{T} 4$ results in a strong increase in the expression of this receptor, similar to the expression of $\alpha \mathrm{SMA}$ under the same conditions. Moreover, T3 and T4 treatment induces transcription of the p75NTR promoter, T3 acting through TR $\alpha 1$ and T4 through cell-surface integrin $\alpha \mathrm{v} \beta 3$. The $-207 /+13$ p75NTR promoter is sufficient for the T3- and T4-induced transcriptional effects. The in vitro effects of T3 and T4 are also observed in livers of rats injected for 3 weeks with TAA, where treatment with $\mathrm{T} 3$ and $\mathrm{T} 4$ increased expression of $\alpha \mathrm{SMA}$ in a statistically significant manner. The lack of effect of TAA and T3 on induction of p75NTR in vivo can be explained both by the fact that in vitro experiments show that T4 is more potent than T3 in increasing p75NTR (threefold $v s$ twofold) and by the fact that in vivo administration of $\mathrm{T} 4$ resulted in significantly higher serum concentrations of total T3 and free T4, compared to administration of $\mathrm{T} 3$.

P75NTR, depending on partnering receptors and on the balance between neurotrophins or proneurotrophins, leads to cell survival or apoptosis. ${ }^{22}$ Expression of p75NTR is increased after injury and inflammation, helping recovery from injury, as in remyelination by Schwann cells. ${ }^{23} \mathrm{TNF} \alpha$, lipopolysaccharide and transcription factor egr-1, are some of the known regulators of p75NTR transcription. ${ }^{23}$ Thyroid hormones may induce transcription of p75NTR directly by binding to TREs in the p75NTR promoter or alternatively, T3 may induce transcription of egr-1, as reported for Schwann cells. ${ }^{24}$ 
a

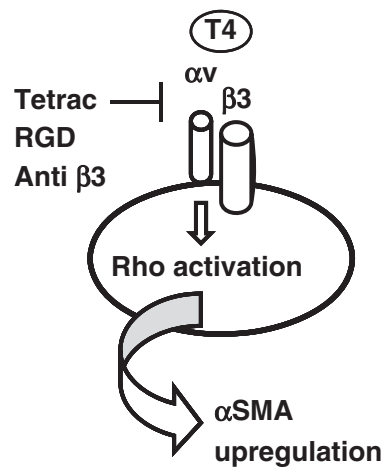

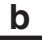

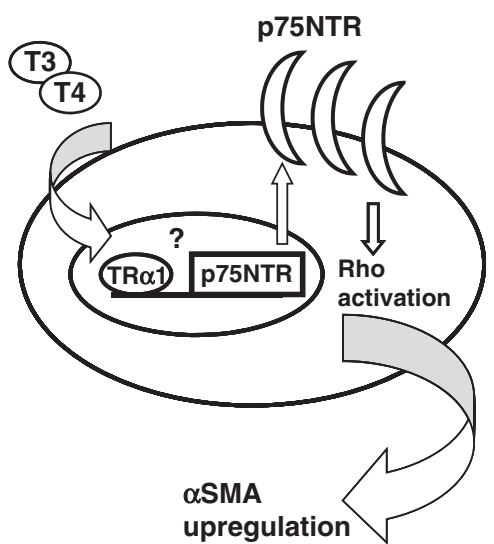

C

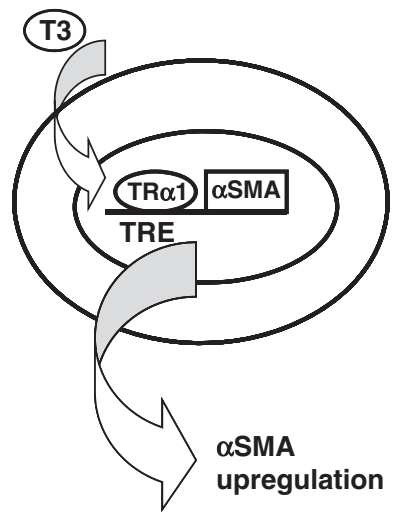

Figure 8 Diagram of mechanisms of activation of HSC mediated by T3 and T4. (a) T4 binds to cell-surface integrin $\alpha$ v $\beta 3$ and induces Rho activation, leading to increased expression of $\alpha$ SMA. T4 binding to integrin $\alpha \mathrm{v} \beta 3$ is blocked by tetrac, RGD and an antibody against $\beta 3$. (b) T3 and T4 enter the cell, and induce transcription of p75NTR, through either TR $\alpha 1$ binding to TREs in the p75NTR promoter, or inducing transcription of other transcription factor (eg, egr-1) that enhance synthesis of the p75NTR gene. Upregulation of p75NTR on the cell surface results in activation of Rho, leading to increased expression of $\alpha$ SMA. (c) T3 binds to TR $\alpha$, which activates $\alpha$ SMA transcription via TREs in the $\alpha$ SMA promoter.

In HSC, p75 NTR has a dual role: in the absence of its ligand NGF, it induces cell activation, ${ }^{23}$ whereas in the presence of NGF, it induces HSC apoptosis. ${ }^{21}$ In the absence of NGF, p75NTR binds Rho inhibitor, Rho-GDI, thus allowing Rho activation. ${ }^{25}$ We show that $\mathrm{T} 3$ and T4 rapidly and directly induce activation of Rho, with no effect on expression of total Rho. This is a newly described signaling pathway for the two hormones. Rho activation regulates cell adhesion, motility, invasion and metastasis through reorganization of cytoskeleton components. ${ }^{26}$ Rho activation is induced by growth factors and extracellular matrix components. ${ }^{26}$ Integrin $\beta 3$ signaling mediates Rho activation, ${ }^{11}$ explaining T4 activation of RhoA by binding to integrin $\alpha \mathrm{v} \beta 3$. T3 activates Rac1, another GTPase, following association of TR $\beta 1$ with the p $85 \alpha$ subunit of the PI3K. ${ }^{25}$ However, in HSC, PI3K is not activated by T3, as shown by unchanged levels of pAkt.

Rho signaling is central to activation of HSC, and inhibition of its downstream signal ROCK by Y-27632, inhibits liver fibrosis and HSC proliferation and activation. ${ }^{11,12}$ Moreover, activation of Rho induces a myofibroblast, $\alpha$ SMAexpressing differentiation program in several cell types. ${ }^{27,28}$ Activation of Rho is followed by activation of ROCK, which phosphorylates non-muscle myosin II, inducing translocation of transcription factors serum response factor and myocardin-related transcriptional activator from the cytoplasm to the nucleus and transcription of $\alpha \mathrm{SMA}^{28}$ In accordance with their effect on Rho activation, we show that thyroid hormones also increase phosphorylation of non-muscle myosin II.

In addition to its effect on HSC activation, T3 has also a pro-inflammatory effect on HSC phenotype, enhancing mRNA expression of TNF $\alpha$ and $\mathrm{SDF} 1 \alpha$, which may also contribute to increasing fibrosis in vivo. Addition of T3 to
TDS does not further increase expression of SFD1 $\alpha$ in fully activated HSC (14 days in culture), as seen in 4 and 7-day cultures, suggesting that $\mathrm{T} 3$ is necessary for regulation of SDF $1 \alpha$ expression only during earlier stages of HSC activation. Expression of $\mathrm{SDF} 1 \alpha$ is strongly induced by in vitro activation of HSC. ${ }^{29}$ Moreover, SDF $1 \alpha$ increases activation of HSC by upregulating $\alpha \mathrm{SMA}$ and collagen I and expression levels of both SDF1 $\alpha$ and its receptor CXRC4 have been shown to be increased in cirrhotic livers of hepatitis $\mathrm{C}$ patients. ${ }^{30}$

MCP-1 expression in HSC can be induced by leptin, prostaglandins, TNF $\alpha$ and lipopolysaccharide, ${ }^{31,32}$ and its expression is regulated by different factors, depending on the activation stage of HSC. ${ }^{33}$ We have not detected any effect of T3 on modulation of MCP-1 mRNA levels in quiescent, activated or fully activated HSC.

Interestingly, we have observed that treatment of $\mathrm{T} 3$ and T4 together with TAA caused liver damage, as shown by high levels of ALT. However, development of liver fibrosis cannot be attributed to apoptosis of damaged hepatocytes, as T3 causes significantly more liver damage than T4, yet T4 is more potent in inducing fibrosis, indicating that fibrosis results from activation of HSC.

In conclusion, thyroid hormones contribute to an activated HSC phenotype by increasing levels of p75NTR, activating Rho and inducing $\alpha \mathrm{SMA}$ and thereby participate in accelerated development of liver fibrosis. Exploring these novel mechanisms may increase the range of therapeutic options for treatment of liver fibrosis.

\section{ACKNOWLEDGEMENT}

This study was supported by a grant from the Israeli Ministry of Health to R Oren. 


\section{DISCLOSURE/CONFLICT OF INTEREST}

The authors declare no conflict of interest.

1. Bataller R, Brenner DA. Liver fibrosis. J Clin Invest 2005;115:209-218.

2. Friedman SL. Mechanisms of hepatic fibrogenesis. Gastroenterology 2008;134:1655-1669.

3. Oren R, Dotan I, Papa $M$, et al. Inhibition of experimentally induced liver cirrhosis in rats by hypothyroidism. Hepatology 1996;24:419-423.

4. Bruck $R$, Weiss $S$, Traister $A$, et al. Induced hypothyroidism accelerates the regression of liver fibrosis in rats. J Gastroenterol Hepatol 2007;22:2189-2194.

5. Yen PM. Physiological and molecular basis of thyroid hormone action. Physiol Rev 2001;81:1097-11142.

6. Kariv R, Enden A, Zvibel I, et al. Triiodothyronine and interleukin-6 (IL-6) induce expression of HGF in an immortalized rat HSC line. Liver Int 2003;23:187-193.

7. Bergh JJ, Lin HY, Lansing $L$, et al. Integrin alpha $V$ beta 3 contains a cell surface receptor site for thyroid hormone that is linked to activation of mitogen-activated protein kinase and induction of angiogenesis. Endocrinology 2005;146:2864-2871.

8. Davis PJ, Leonard JL, Davis FB. Mechanisms of nongenomic actions of thyroid hormone. Front Neuroendocrinol 2008;29:211-218.

9. Zhou X, Murphy FR, Gehdu N, et al. Engagement of alpha v beta3 integrin regulates proliferation and apoptosis of HSC.J Biol Chem 2004;279:23996-24006.

10. Passino MA, Adams RA, Sikorski SL, et al. Regulation of HSC differentiation by the neurotrophin receptor p75NTR. Science 2007;315:1853-1856.

11. Iwamoto $\mathrm{H}$, Nakamuta $\mathrm{M}$, Tada $\mathrm{S}$, et al. p160 ROCK-specific inhibitor Y-27632, attenuates rat HSC growth. J Hepatol 2000;32:762-770.

12. Murata T, Arii S, Nakamura T, et al. Inhibitory effect of Y-27632, a ROCK inhibitor, on progression of rat liver fibrosis in association with inactivation of HSC. J Hepatol 2001;35:474-481.

13. Oakley F, Trim N, Constandinou CM, et al. Hepatocytes express nerve growth factor during liver injury: evidence for paracrine regulation of HSC apoptosis. Am J Pathol 2003;163:1849-1858.

14. Asai K, Tamakawa S, Yamamoto $M$, et al. Activated HSC overexpress p75NTR after partial hepatectomy and undergo apoptosis on nerve growth factor stimulation. Liver Int 2006;26:595-603.

15. Kumar A, Sinha RA, Tiwari M, et al. Hyperthyroidism induces apoptosis in rat liver through activation of death receptor-mediated pathways. J Hepatol 2007;46:888-898.

16. Bauer A, Mikulits W, Lagger G, et al. The thyroid hormone receptor functions as a ligand-operated developmental switch between proliferation and differentiation of erythroid progenitors. EMBO J 1998;17:4291-4303.

17. Gosteli-Peter MA, Harder BA, Eppenberger HM, et al. Triiodothyronine induces over-expression of alpha-smooth muscle actin, restricts myofibrillar expansion and is permissive for the action of basic fibroblast growth factor and insulin-like growth factor I in adult rat cardiomyocytes. J Clin Invest 1996;98:1737-1744.

18. Collie ES, Muscat GE. The human skeletal alpha-actin promoter is regulated by thyroid hormone: identification of a thyroid hormone response element. Cell Growth Differ 1992;3:31-42.

19. Hiroi $\mathrm{Y}$, Kim HH, Ying $\mathrm{H}$, et al. Rapid nongenomic actions of thyroid hormone. Proc Natl Acad Sci USA 2006;103:14104-14109.

20. Yamashita T, Tucker KL, Barde YA. Neurotrophin binding to the p75 receptor modulates Rho activity and axonal outgrowth. Neuron 1999;24:585-593.

21. She $\mathrm{H}$, Xiong $\mathrm{S}, \mathrm{Hazra} \mathrm{S}$, et al. Adipogenic transcriptional regulation of hepatic stellate cells. J Biol Chem 2005;280:4959-4967.

22. Barker PA. p75NTR is positively promiscuous: novel partners and new insights. Neuron 2004;42:529-533.

23. Cragnolini $A B$, Friedman WJ. The function of p75NTR in glia. Trends Neurosci 2008;31:99-104.

24. Mercier G, Turque N, Schumacher M. Rapid effects of triiodothyronine on immediate-early gene expression in Schwann cells. Glia 2001; 35:81-89.

25. Storey NM, O'Bryan JP, Armstrong DL. Rac and Rho mediate opposing hormonal regulation of the ether-a-go-go-related potassium channel. Curr Biol 2002;12:27-33.

26. DeMali KA, Wennerberg $K$, Burridge $K$. Integrin signaling to the actin cytoskeleton. Curr Opin Cell Biol 2003;15:572-582.

27. Bourgier C, Haydont V, Milliat F, et al. Inhibition of Rho kinase modulates radiation induced fibrogenic phenotype in intestinal smooth muscle cells through alteration of the cytoskeleton and connective tissue growth factor expression. Gut 2005;54:336-343.

28. Fan L, Sebe A, Péterfi $Z$, et al. Cell contact-dependent regulation of epithelial-myofibroblast transition via the rho-rho kinase-phosphomyosin pathway. Mol Biol Cell 2007;18:1083-1097.

29. Jiang F, Parsons CJ, Stefanovic B. Gene expression profile of quiescent and activated rat hepatic stellate cells implicates Wnt signaling pathway in activation. J Hepatol 2006;45:401-409.

30. Hong F, Tuyama A, Lee TF, et al. Hepatic stellate cells express functional CXCR4: role in stromal cell-derived factor-1alpha-mediated stellate cell activation. Hepatology 2009;49:2055-2067.

31. Efsen $E$, Bonacchi $A$, Pastacaldi $S$, et al. Agonist-specific regulation of monocyte chemoattractant protein-1 expression by cyclooxygenase metabolites in hepatic stellate cells. Hepatology 2001;33:713-721.

32. Paik $\mathrm{YH}, \mathrm{Sch}$ wabe RF, Bataller $\mathrm{R}$, et al. Toll-like receptor 4 mediates inflammatory signaling by bacterial lipopolysaccharide in human hepatic stellate cells. Hepatology 2003;37:1043-1055.

33. Sprenger $H$, Kaufmann A, Garn $H$, et al. Differential expression of monocyte chemotactic protein-1 (MCP-1) in transforming rat hepatic stellate cells. J Hepatol 1999;30:88-94. 